\title{
TRANSIENT AND DYNAMIC PERFORMANCE OF A HIGH-LOADED SWNCHRONOUS GENERATOR WITH PID POWER SYSTEM STABILIZER
}

\author{
M.A. MORSY SHANAB ${ }^{\star}$ F.A. KHALIFA ${ }^{\star} \quad$ W. SABRY ${ }^{\star \star}$
}

\section{ABSTRACT}

This paper presents a study of the control and stability of a synchronous generator connected to an infinite bus via two parailel transmission lines when the system operate at high loading conditions and subjected to different disturbances.

An effective mean of damping the oscillations resulting from the disturbances is to provide the synchronous generator with power system stabilizer (PSS). An adaptive proportionalplus-integral-plus-derivative (PID) PSS is suggested in this paper. In this technique, the controller parameters (proportional, integral, and derivative constants) are not fixed but they are computed and updated according to the system operating conditions.

Different stabilizing signals are used for the PID-PSS. Each signal is weighted by a factor used arbitrary to get the best performance of the generator under these conditions.

The computer results obtained from simulation study are compared with the results of the system without a controller.

* Maj. Gen. Prof. Dr. Eng., Dpt. of Elect. Power and Energy, M.T.C., Cairo, Egypt.

* Col. Dr. Eng., Dpt. of Elect. Power and Energy, M.T.C., Ca1ro, Egypt.

*** Capt. Eng., Ass. Teacher, Dpt. of Elect. Power and Energy, M.T.C., Cairo, Egypt. 


\section{INTRODUCTION}

The problem of stability of synchronous generators has received and will receive a great deal of attention. The recent trends in power systems design is toward the application of a generating units of large size to feed high loads. Therefore, a control system is required to provide the compensation with which the reduction in stability margin is offset [1].

stability analysis of a large electric power system depends almost entirely on digital computer simulation of system dynamic behaviour. Simulation implies the existance of mathematical models for a variety of apparatus, data files which contain model parameters for specific power systems and computer programs.

The application of adaptive PID-PSS to a synchronous generator connected to an infinite bus through two parallel transmission lines is considered. A nonlinear mathematical model for this system is prepared. The influence of the proposed PSS on the transient and dynamic performance of the synchronous generator is investigated, when the system is subjected to different disturbances and operating at high loading conditions.

\section{THE POWER SYSTEM MODEL}

The power system under consideration is shown in Fig.l. It consists of a synchronous generator connected to a large power system through a power transformer and two parallel transmission lines.

The mathematical model of the power system given in Fig.l, is based on the state-space formulation [2-5]. In this model, the state-space variables are chosen to be the currents. This can be expressed in the matrix form as :

where :

$$
[\dot{I}]=[A] \cdot[I]+[B] \cdot[U] \text { p.u. }
$$

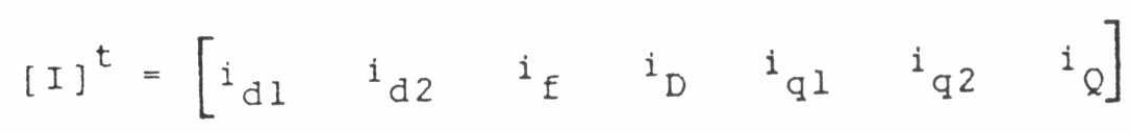

The torque equation can be expressed in the form of :

$$
\tau_{j} \cdot \dot{\omega}=T_{m}-T_{e}-T_{d} \quad \text { p.u. }
$$

where :

$$
\mathrm{T}_{\mathrm{d}}=\mathrm{D} \cdot \omega \text { p.u. }
$$

Also, the relation between $\delta$, and $\omega$ can be defined as :

$$
\dot{\delta} \Delta \omega-1 \quad \text { p.u. }
$$

The excitation system with which the synchronous generator is equipped is a static type l-s exciter [1] and its block diagram is shown in Eig.2. The equations of the excitation system can be written in the state-space form as following: 


$$
\begin{aligned}
& {\left[\begin{array}{c}
\dot{E}_{\mathrm{fD}} \\
\dot{V}_{3}
\end{array}\right]-\left[\begin{array}{cc}
-1 / \mathrm{T}_{\mathrm{A}} & -\mathrm{K}_{\mathrm{A}} / \mathrm{T}_{\mathrm{A}} \\
-\mathrm{K}_{\mathrm{f}} /\left(\mathrm{T}_{\mathrm{A}} \cdot \mathrm{T}_{\mathrm{f}}\right) & -\left(\frac{\mathrm{K}_{\mathrm{f}} \mathrm{K}_{\mathrm{A}}}{\mathrm{T}_{\mathrm{f}} \mathrm{T}_{\mathrm{A}}}+\frac{1}{\mathrm{~T}_{\mathrm{f}}}\right)
\end{array}\right]\left[\begin{array}{c}
\mathrm{E}_{\mathrm{fD}} \\
\mathrm{V}_{3}
\end{array}\right]+} \\
& {\left[\begin{array}{l}
\frac{K_{A}}{T_{A}}\left[v_{4}+\frac{E_{O A}}{K_{A}}\right] \\
\left.\frac{K_{E} K_{A}}{T_{E} T_{A}}\left(v_{4}+\frac{E_{O A}}{K_{A}}\right)\right]
\end{array}\right]} \\
& \text { p.u. }
\end{aligned}
$$

By feeding-back the terminal voltage signal and comparing this signal with a reference value, the excitation system is related to be an automatic voltage regulator (AVR).

Combining equations (1), (4) and (5), the complete system model will be constructed.

\section{DESIGN OF THE PROPOSED PSS}

In this paper, a proposed PID-PSS is designed. The ters of this controller are not constant but they are computed according to the variation of the system operating conditions. Fig. 3 shows block diagram of the controlled conditions. Fig. 3 shows block
process, AVR, and the proposed pSs. Reference [6] shows the
method on which the design is depended. For a wide range of system operating conditions, (active power (P), and reactive power (Q)), the obtained controller parameters are stored in look-up table against the system operating conditions. During on-line operation, the controller monitors the $P$ and $Q$ values of the system and picks up the corresponding controller parameters at each sampling instant. The system equation are :

$$
\begin{aligned}
& \dot{X}=A \cdot X+B \cdot u \\
& Y=C \cdot X
\end{aligned}
$$

where

$$
[I]^{t}=\left[\begin{array}{lllllllllll}
i_{d l} & i_{d 2} & 1_{f} & i_{D} & i_{q 1} & 1_{q 2} & i_{Q} & E_{f D} & v_{3} & \omega & \delta
\end{array}\right]
$$

Taking the laplace transform for equations (6), and (7):

$$
\begin{aligned}
S \cdot X(S) & =A \cdot X(S)+B \cdot U(S) \\
Y(S) & =C \cdot X(S)
\end{aligned}
$$

Equation ( 8 ) can be rewritten as :

$$
X(S)=(S \cdot I-A)^{-1} \cdot B \cdot U(S)
$$


The control signal is:

$$
\begin{aligned}
U(S) & =H(S) \cdot Y(S) \\
\therefore U(S)= & \frac{S \cdot T_{W}}{I+S \cdot T_{W}} \cdot\left[K_{p}+\frac{K_{I}}{S}+K_{D} \cdot S\right] \cdot Y(S)
\end{aligned}
$$

From equations (9), and (10) we have:

$$
Y(S)=C \cdot(S \cdot I-A)^{-1} \cdot B \cdot U(S)
$$

So,

$$
\begin{aligned}
H(S) & =\frac{1}{C \cdot(S \cdot I-A)^{-1} \cdot B} \\
& =\frac{S \cdot T_{W}}{1+S \cdot T_{W}} \cdot\left[K_{p}+\frac{K_{I}}{S}+K_{D} \cdot S\right]
\end{aligned}
$$

The gains $K_{P}, K_{I}$, and $K_{D}$ may be computed by finding the eigen values of the open loop system, prespecifying the eigen values of the closed loop system, and substituting the three eigenvalues in equation (14), we get three equations when solved together we get $K_{P}, K_{I}$, and $K_{D}$. The input signal to the PSS may be expressed as :

$$
\mathrm{V}_{\mathrm{FSS}}=\mathrm{w}_{1} \cdot \Delta \omega+\mathrm{w}_{2} \cdot \Delta \delta+\mathrm{w}_{3} \cdot \Delta \rho
$$

4. SYSTEM PARAMETERS, RESULTS, AND DISCUSSION

To verify the proposed analysis given in this paper, the system data are given in references $[2,6]$ as :

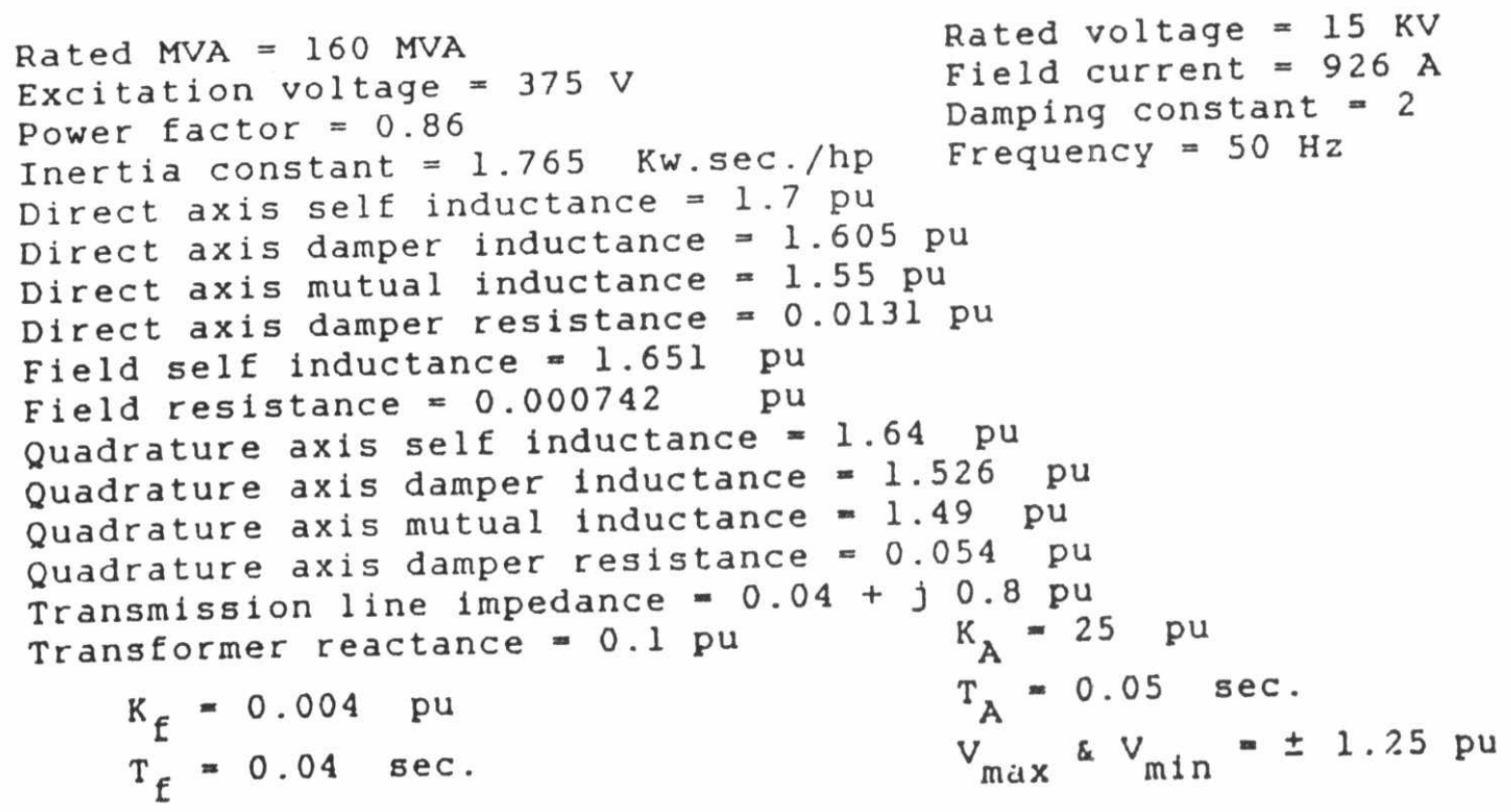


The power dellvered to the large bus system was consldered to be :

$$
p=1.25 \text { p.u., and } Q-0.75 \text { p.u. }
$$

The controller constants was found to be :

$$
K_{P}=31.17, \quad K_{I}=-187.65 \mathrm{sec}^{-1} \text {, and } K_{D}=641.33 \mathrm{sec} \text {. }
$$

The weighting factors of the input signals of the pss are:

$$
w_{1}=2.91, \quad w_{2}=0.091 \text {, and } \quad w_{3}=0.065
$$

A disturbance is considered and simulated as a short circuit in one transmission line at its midpoint with a successful reclosure of the circuit breakers. We breakers are the short circuit remain for 0.08 second and the reclosed after 0.16 second. curves are shown in Fig.4-a, 5-a,

The generator response curvesed PSS has high capability in and $6-a$. They show that the properator in comparison with improving the performance of transient response of such a that of conventional Ave

\section{CONCLUSIONS}

In this paper, the transient and dynamic performance of a synchronous generator when equipped with a continuous acting AVR and adaptive PID-PSS is described. The effect stabilizing signals on the generator response ls alsont mean for

The proposed PID-PSS is proved to be an efficlent dynamic improving the synchronous generator under high loads at a stability when the generator
severe disturbance condition.

\section{REFERENCES}

1. Demel10, F.P., Ewart, D.N., and Temoshok, M.," "stability of synchronous machines as affected by excitation systems, Machine and system parameters", Proc. American Power Conf. Vol. XXVII, PP. 1150-1159 (1965). "Power system control and

2. Anderson, P.M., and Fouad, A.A.' The Iowa State University (1977). stability", Vol.l, Book, Themsis and stability", Book,

3. Jha, R.S., "Power systemlishers, New Delhi (1980).

4. Uppal, S.L., "Electrical power", Book, Khana publishers, New Delhi (1985).

5. Bergen, A.R., "Power system analysis", Prentice-Hald Jersey (1986).

6. HSU, Y.Y. ' and the auto-searching method", IEEE Trans. of machine ustems, Vol.3, No.4, November (1988). 


\section{NOMENCLATURE}
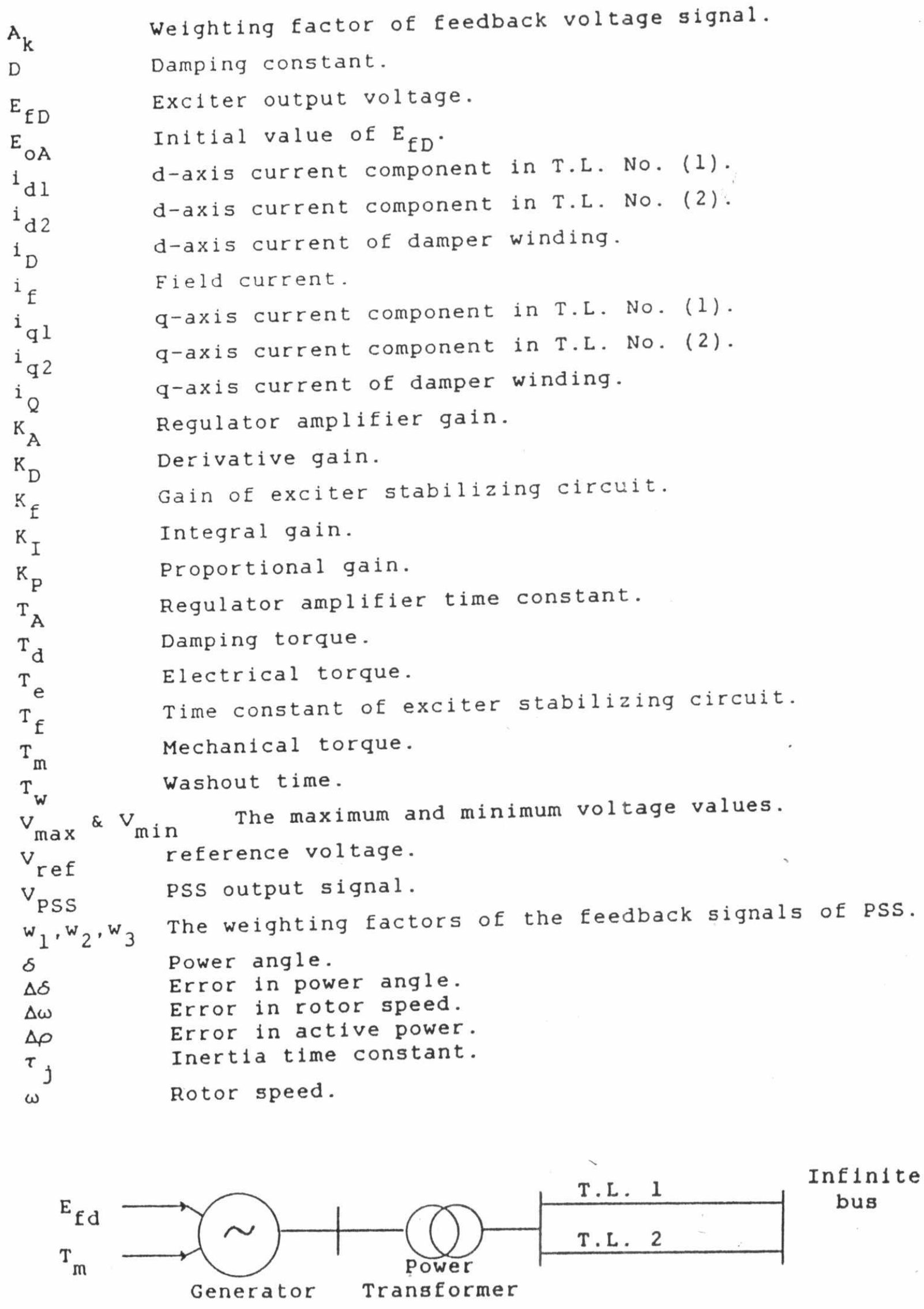

F1g.1. The power sygtem 


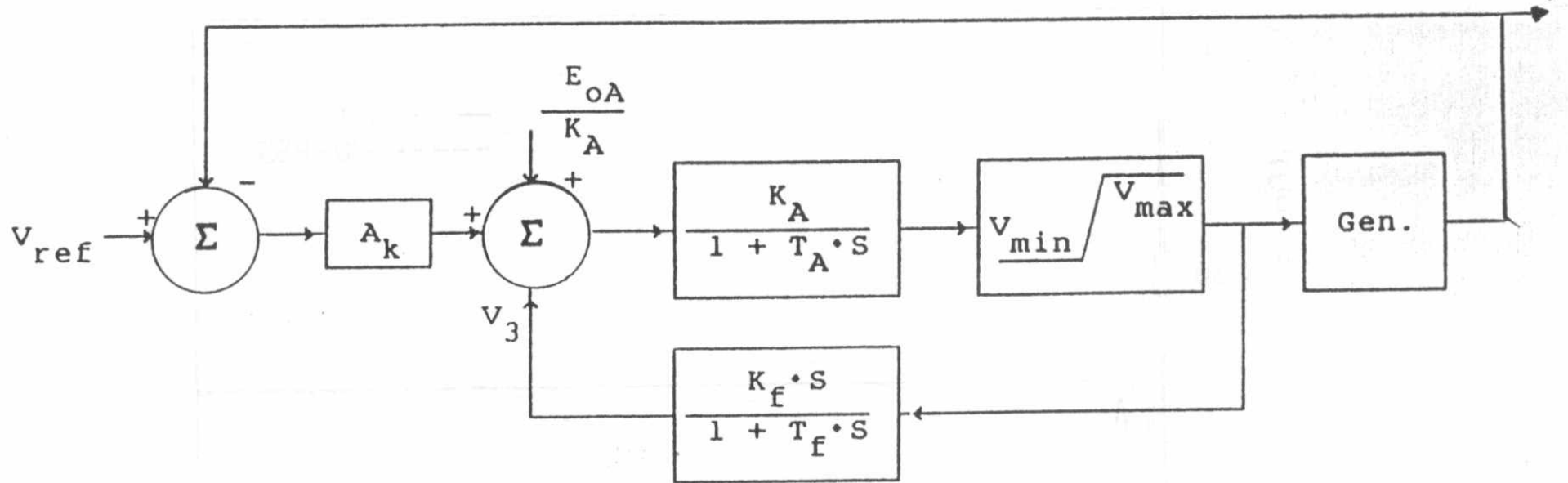

Fig.2. Block diagram of AVR

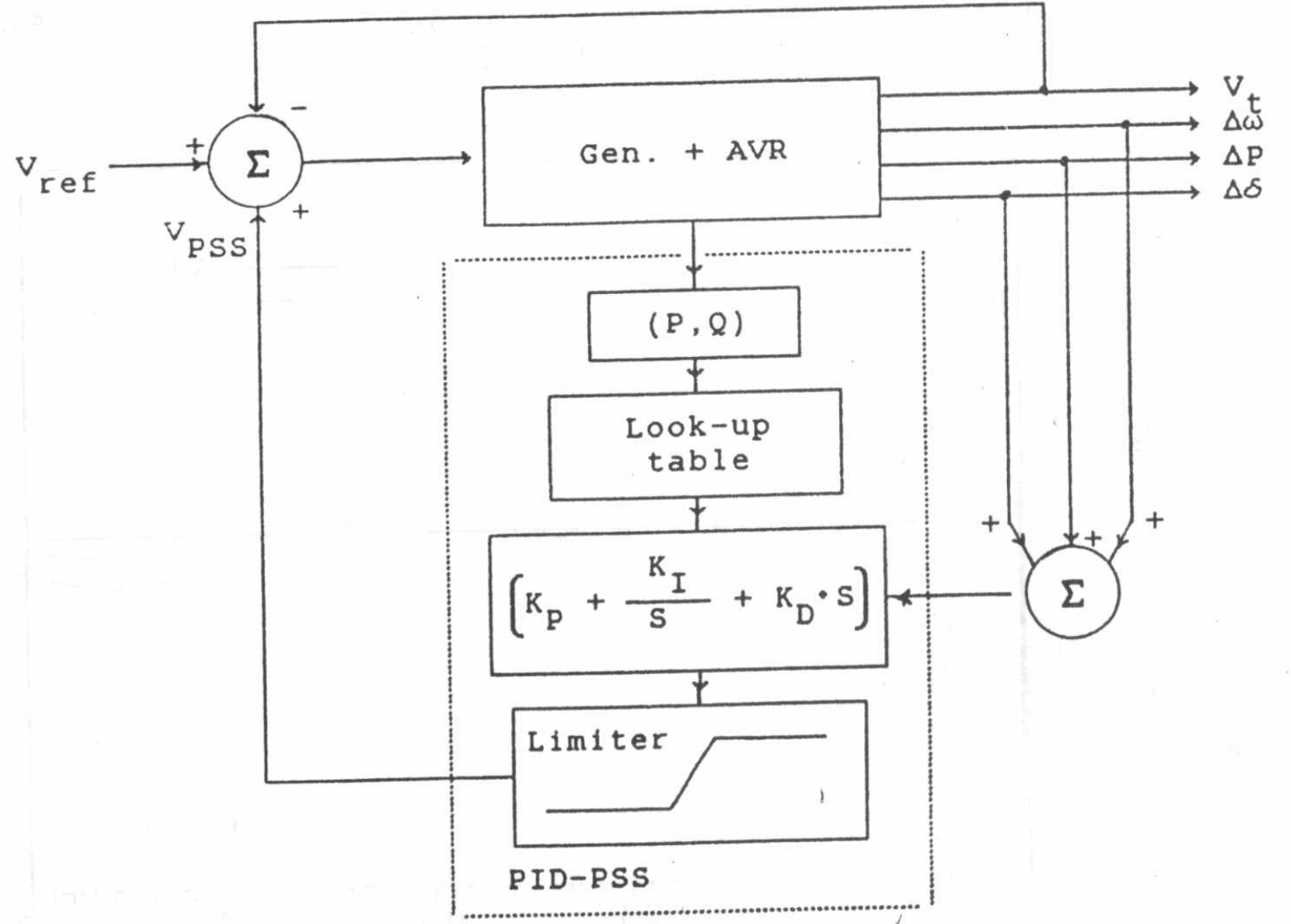

Fig.3. Block diagram of the PID-PSS 

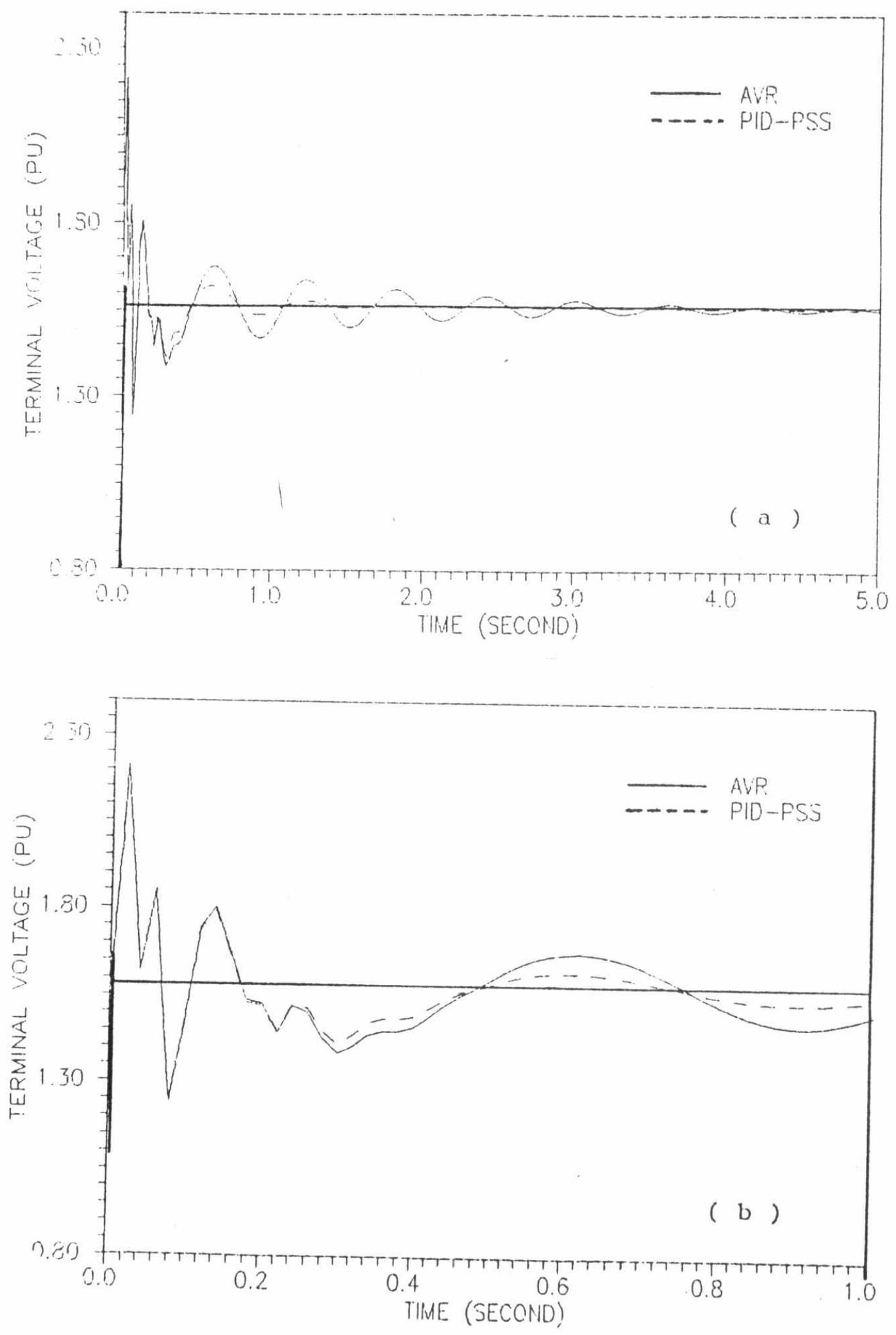

Fig.4. Terminal voltage/time curve 

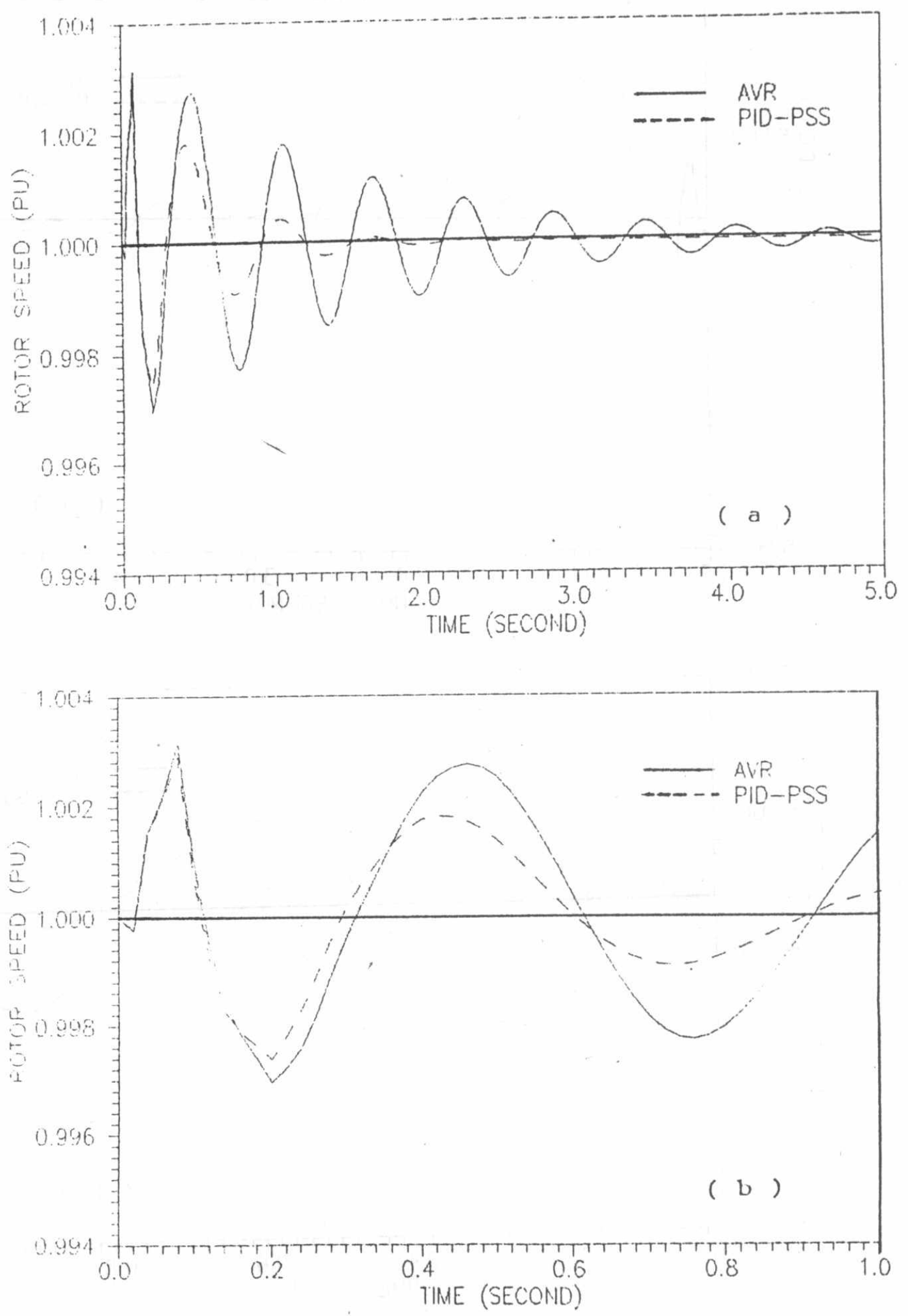

Fig.5. Rotor speed/time curve 

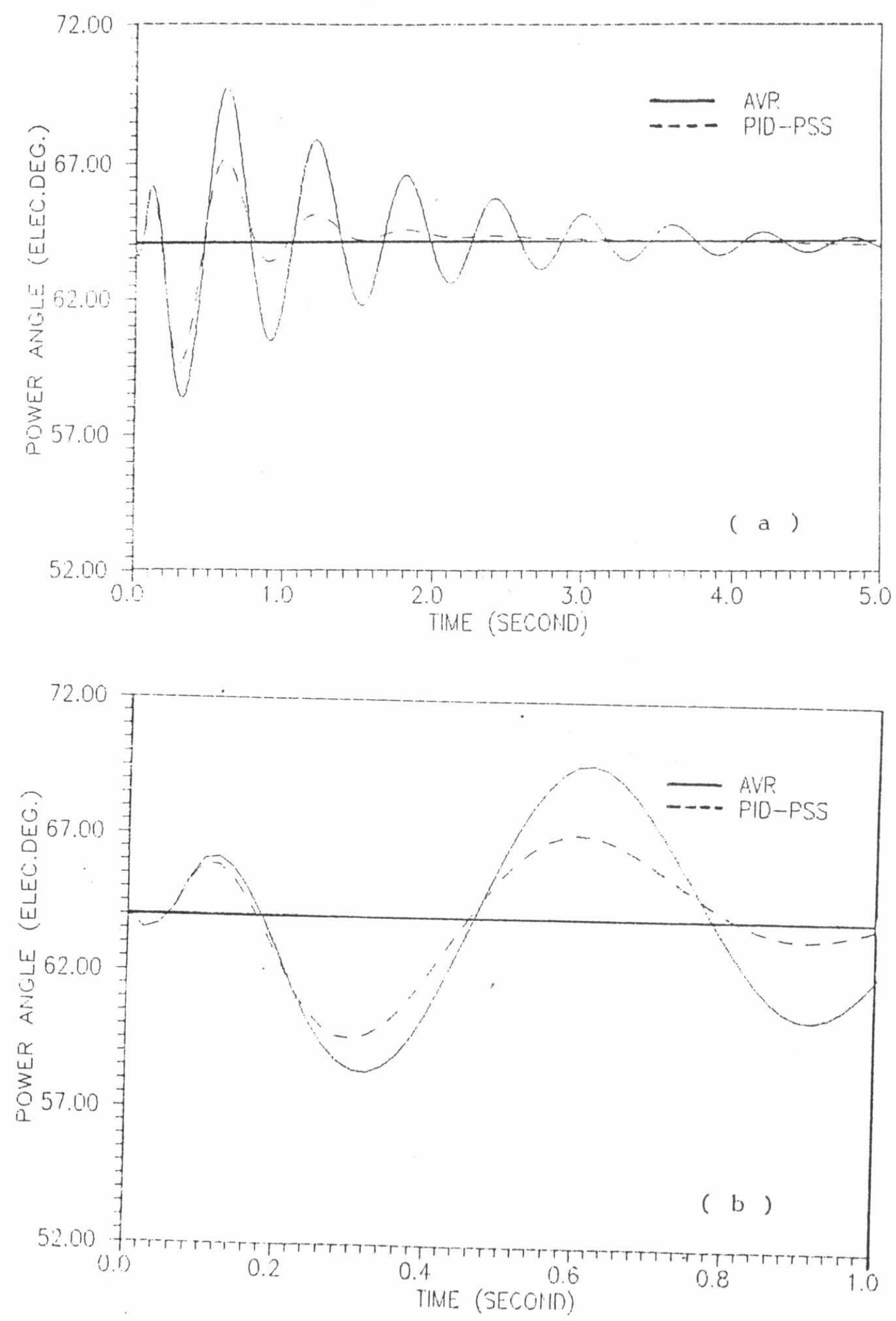

Fig.6. Power angle/time curve 